\title{
A Survey of Monitoring and Evaluation Systems for Government Projects in Tanzania: A Case of Health Projects
}

\author{
Mpawe N. Mleke \\ Nelson Mandela African Institution of Science and Technology, P. O. Box 447, Arusha, Tanzania \\ Email: mlekem@nm-aist.ac.tz or mpamleke@gmail.com \\ Mussa Ally Dida \\ The Nelson Mandela Institution of Science and Technology, P. O. Box 447 Arusha, Tanzania \\ Email: mussa.ally@nm-aist.ac.tz
}

Received: 06 August 2019; Accepted: 24 September 2019; Published: 08 February 2020

\begin{abstract}
Monitoring and Evaluation (M\&E) system are used across the world by organizations or governments to track progress, measure and evaluate outcomes of projects. Organizations can improve their performance, effectiveness and achieving results in project success by strengthening their monitoring and evaluation systems. Moreover, various studies reveal the need for information and communication technology systems in monitoring and evaluation activities because most of the government organizations do not employ computerized monitoring and evaluation systems and those having these systems lack a systematic early informing mechanism of the projects' progress. Currently, the Ministry of Health in Tanzania monitors and evaluates its projects manually, due to this, they face the risks and challenges during the implementation of projects because of a lack of having timely adoption of remedial action. Monitoring and evaluation staffs spent a lot of time in manual work, manual compilation of data, due to data being in separate systems, delay in submission of data, data is lost between primary registries to monthly summaries, from monthly to quarterly summaries, system does not contain all details about projects/program as well as budget information, no early alert information about the status of the project, poor information sharing among stakeholder.

In this study, we collect representative data from three monitoring and evaluation staff, four ICT staff and five project members by using interviews, focus group discussion and document review. The result showed that the electronic monitoring and evaluation system will solve a presented challenge. Development of a web-based monitoring and evaluation system for the ministry of health projects will provides timely, accurate information, that for tracking the implementation progress of projects improved monitoring and evaluation.
\end{abstract}

Index Terms-Health Projects, monitoring and evaluation system, web-based, Ministry of health

\section{INTRODUCTION}

The Tanzanian government has shown much effort recently in improving the lives of its citizens, by initiating and implementing different programs/projects in various sectors such as community empowerment and health [1]. Ministry of Health, Community Development, Gender, Elderly and Children (MOHCDGEC) in Tanzania, is committed to provide basic health care services that are good, equitable, quality, affordable, accessible, gender sensitive and sustainable.

The project is a process containing a set of controlled activities and coordinated with time framework to achieve objectives. Monitoring is an ongoing activity which involves the collection and data analysis in order to track the progress of the project implemented against objectives and selected indicator. Evaluation is a process of assessing, measuring, observing the ongoing or completed projects [2]. Monitoring and Evaluation is a system used by organizations/governments to assess and manage the performance of a project against the plan and desired output/result [3]. Performance on project activities information is based on schedule, cost, scope, quality and resources [4]. In today's world, M\&E provides the performance of programs, projects and government policies and it classifies the things to do and not to do and it gives the reasons why[5].

Studies reveal that organizations can improve their performance, effectiveness and achieve good results by employing M\&E systems to their projects [6]. According to [7], a web-based monitoring and evaluation system is a tool characterized by a number of users who visit a web page to view information or update and to check the status of projects.

This paper presents a survey of the M\&E systems for health projects at the ministry of health in Tanzania government projects and the challenges that they are facing. A web-based M\&E system has then proposed a 
solution to the challenges found in the available systems. In this paper, the organization is as follows: section one present the introduction of this study, section two explains the problem statement on the current situation in monitoring and evaluation system and its challenges. Section three presents the related studies and section four methods used for data collection and results. Section five describes the proposed system with requirements and lastly the discussion and conclusion.

\section{BACKGROUND}

Currently, the Ministry of Health monitors and evaluates its projects manually as a result, there is a lack of timely adoption of remedial action for the risks encountered. Data collection, reporting, and management are not uniform for different projects sponsored by different donors within the ministry [8]. This can be solved by having an electronic system that provides accurate information for monitoring and evaluating the projects in timely.

From 2008 to 2013, the National malaria control program (NMCP) faced the challenge of coordinating the collection of monitoring and evaluation information [9].

On other hand, the Health Sector Strategic Plan III (2009-2015), highlighted the lack of coordination among information and communication technology departments, ministries, agencies and partners, lack of monitoring and evaluation process in epidemics such as tuberculosis (TB), malaria and AIDS /HIV due to inefficiencies and poor infrastructure of the healthcare system [10].

Despite the reported increasing demand from donorfunded health programs on the use of electronic M\&E system to improve data quality, data access, reduce workload, accurate report and data analysis [11], such systems are not available at the Ministry of Health.

This study aims to develop a web-based monitoring and evaluation system with appropriate indicators to be used to track and report the status of projects and allow prompt actions to mitigate the risks and challenges encountered. Moreover, the proposed system will help to simplify work and generate quality data for effective planning and successful project implementation. It will provide collaboration, network, capacity building to staff and stakeholder/donor[12].

\section{RELATED WORKS}

Recently, the use of $\mathrm{M} \& \mathrm{E}$ tools is important in tracking and judging the progress of any project. Monitoring and evaluation provide performance on projects' progress and measure whether the project is meeting its objectives or progressing in the right direction. Recent studies show that there have been an increase in awareness creation on M\&E in public and private and organizations, together with an increase of institutions that offer M\&E courses [13]. However, M\&E systems in most organizations are manually operated.
A study by [14], on non-government maternal health projects in Kenya, recommends on increasing the number of $M \& E$ staff training, investing in information and communication technology, involving stakeholder in monitoring and evaluation process to provide better feedback on achieving quality data and having routine data quality and using the M\&E plans.

The study of [15] was conducted in Kenya to determine the $M \& E$ factors that influence the success of development projects, the success of the project depends on the selection of good tools and techniques, monitoring team, M\&E plan and availability of fund. Having all this enables the $M \& E$ activities for a project to be performed well and having a good result.

A report by UNESCO shows that most governments have data systems, sophisticated or simple for measuring the results of any program on the target population /group and the cost-effectiveness of their spending and the outputs of the program [16]. The report further indicates that few governments have acquired a monitoring and evaluation system in place to monitor and evaluate performance in terms of outcomes of all their programs. It is also reported that few countries in the developed world have a well M\&E system as a result has developed high performing, dynamic and sustainable projects.

[6] Developed a web-based monitoring and evaluation system for highway and road projects for the aims of providing information concerning road projects and easily accessed by any user or public. The study reaches the goal of improving road project monitoring and helps the Department of Public Works and Highways at Philippine government.

In Kenya, a study by [17] on Water, Sanitation Hygiene (WASH) program under Africa Medical and Research Foundation (AMREF), reported poor participation in activities like data collection, preparation of M\&E timetables, designing, identification of indicators, decision making and feedback which are very crucial. The study however failed to suggest a solution to improve the participation of leaders and organizations to make a good performance in $M \& E$ activities.

According to [18] on the development of design evaluation and feedback tools, a web-based tool for education was used to support them for collection and report the data for learning, teaching and research. This web-based tool was developed due to the need of students, researchers and instructors to be used in projects design education. This web-based tool can be adopted in the ministry of health of Tanzania to help them to simplify the implementation of project activities and to allow feedback from different stakeholders.

In the study of [19], to determine the effective M\&E in health services in Kenya, there was poor information and data sharing among stakeholders and the provision of healthcare services. The recommendation of this study was to insist the M\&E practitioners to be trained and to have seminars in order to avoid the existing challenge but they didn't suggest to have the web-based monitoring and evaluation system for Healthcare service to simplify the 
collection of data and easy to share the information among stakeholder.

The study of [20] proposes M\&E system for employees and organization performance for the ministry of industry and trade in Egypt. The system helped top management, the feedback from customers and employee performance were increased as well as regular reports. However, the study did not indicate an automatic planning section for a comparison between the achievements and the plans.

In a similar study, [21] to develop a web-based construction project performance monitoring system. The aim was to assist the project manager in construct projects control and measure the performance in terms of quality, people, time, cost, client satisfaction and communication. Even with a cost used in setting the internet in the database system, but require good security to prevent hacker attack and downtime and constant monitoring.

In the agriculture and natural resources projects (20052010) at Sokoine University of Agriculture in Tanzania supported by the Norwegian government [22], a webbased M\&E system was implemented in order to build the capacity of smallholder farmers and traders to satisfy their demand for knowledge, communication, technology, improve the dissemination of information and ease the M\&E task. Despite its goal, the scope of this research was small and other M\&E continued to be manually operated, hence less effective and efficient.

The literature reveals that most government organizations do not employ computerized M\&E systems and those having these systems lack a systematic early informing mechanism of the projects' progress. This study aims to develop a web-based M\&E system to keep track of implementation progress, give alerts on the success or failure of individual projects with their own sub-goals that contribute to overall performance.

\section{MATERIAL AND METHODS}

\section{A. Case Study}

The study was conducted at the Ministry of Health, Community Development, Gender, Elderly and Children (MOHCDGEC) in Dodoma and Dar es Salaam region, where different health projects are monitored and evaluated. This research was focused on collecting, identifying and analyzing different monitoring and evaluation practices for various projects of the Ministry of Health in Tanzania.

\section{B. Sample Size}

The study involved a total of 12 respondents from different departments, three monitoring and evaluation staff, four ICT staff and five projects/program members. The study selects the representatives who work at the Ministry of health with enough experience in the implementation of M\&E activities and ICT skills.

\section{Data Collection Methods}

To obtain the required information, both secondary and primary sources of data collection were used. The data was collected using document review, focus group discussion and interview as follows:

Document review: The main objective of selecting this tool was to understand the background information of the existing system how it operates before moving forward and help to formulate the questions for the interview and focus group discussion[23]. The documents reviewed were weekly, monthly, quarterly and annual project reports as well as reports generated by HMIS/DHIS. This was done in order to understand the main information/data that are required in programs/projects and to identify the key performance indicators, activities and targets [24].

Interview: The interview covered project members responsible for programs of malaria, Tuberculosis and HIV/AIDS. The interview was conducted using a semistructured interview to allow them to express their opinion, experience, give out their general views and know the complex issues [25]. The interview guide was based on how they collect data, the method/tools which are used for data collection and the challenges that project members face in the implementation of projects/programs [23].

Focus group discussion: This method helps to understand the participants how they think about new ideas through interaction [26]. The focus group was conducted with M\&E and ICT staff. The aim was to analyze the current monitoring and evaluation system performance and tools used to monitor and evaluate projects and the current system used to collect and manage data (data storage system) which are used to collect the routine information about the projects. Another discussion was based on the challenges the monitoring and evaluation staffs face in practice and implementation of the M\&E system in different projects.

\section{Data analysis method}

Qualitative analysis methods were employed in this study to get what is required for analyzing a current monitoring and evaluation system for the ministry of health projects in Tanzania.

\section{RESUlTS}

\section{A. Result from Focus Group Discussion}

Overview of the existing system: The ministry of health in Tanzania contains four levels which are health facility, district, regional and national level. Data recording and reporting systems in the ministry include paper-based (patient cards, registers, logbooks, summary forms) and an electronic database system (hospital record books, tally sheet, data collection books and monthly report form) from Health management information system/district health information system (HMIS/DHIS). 
In health facility level (health care workers) data is recorded in the paper-based format/system. For example, in $\mathrm{TB} /$ malaria programs, data is obtained from the patient card, TB register and, a daily, weekly and monthly paper report is created. Individual-level, patient data are also collected using tally sheets and reported through monthly summary forms, then the heads of departments in each facility submit monthly summary forms report to the district level [27].

The district levels receive; review the papers-based report from the health facility levels and record into DHIS/HMIS. The regional level is a part where monitoring and evaluation are carried out by reviewing data that are entered by the district level and from other own projects system due to door preference by checking the target, indicator and objectives activities if it is achieved, verify, analyze and generate a report manually for regional use.

Lastly, the National level is where the central, partner or stakeholder receive the report and provide the feedback and disseminate. Fig. 1 presents the current system on how they monitor and evaluate the government project at the ministry of health in Tanzania.

Challenges for current monitoring and evaluation system: Currently the Ministry of Health monitors and evaluates its projects manually; the study found that M\&E staff spent a lot of time in manual work and the current system lack necessary details about projects. All participants who were involved in this study from M\&E and ICT office responded that "there are difficulties in accomplishing the projects on time, poor information sharing among stakeholders and lack of early alert information about the status of the project". Moreover, "difficult to have early alert information when implementation risks and challenges are encountered". Having a good M\&E framework enables the ministry to track and assess the result of health projects.

\section{B. Result from Interview}

Available tools: The program members of malaria and AIDS program indicate that "the current system used to collect and report routine health data at the ministry of health is an electronic database such as district health information system and health management information system (DHIS/HMIS)"'. The DHIS adapted/customized to support HMIS implementation and operates in a government hospital, all district levels and regions, DHIS supports monthly data captured by the facility. The DHIS/HMIS contains clinical data; the clinical data are data collected during ongoing patient care or part of a formal clinical trial program or the information about the health status of the health care of patients received over a specific time [28].

Two program members responded that "in DHIS/HMIS it contains facility, hospital record books, tally sheet, monthly report form and data collection books and paper-based systems such as patient card, logbook, registers and monthly summary form" [29].

Challenges for available tools: The study revealed that there are some difficulties in available tools such as manual compilation of data due to the data are being in a separate system and delay in the submission of data. Also, respondents claimed that "data is lost between primary registries to monthly summaries, from monthly to quarterly summaries" and no or little feedback on data reported from a higher level and sustainability of the system.

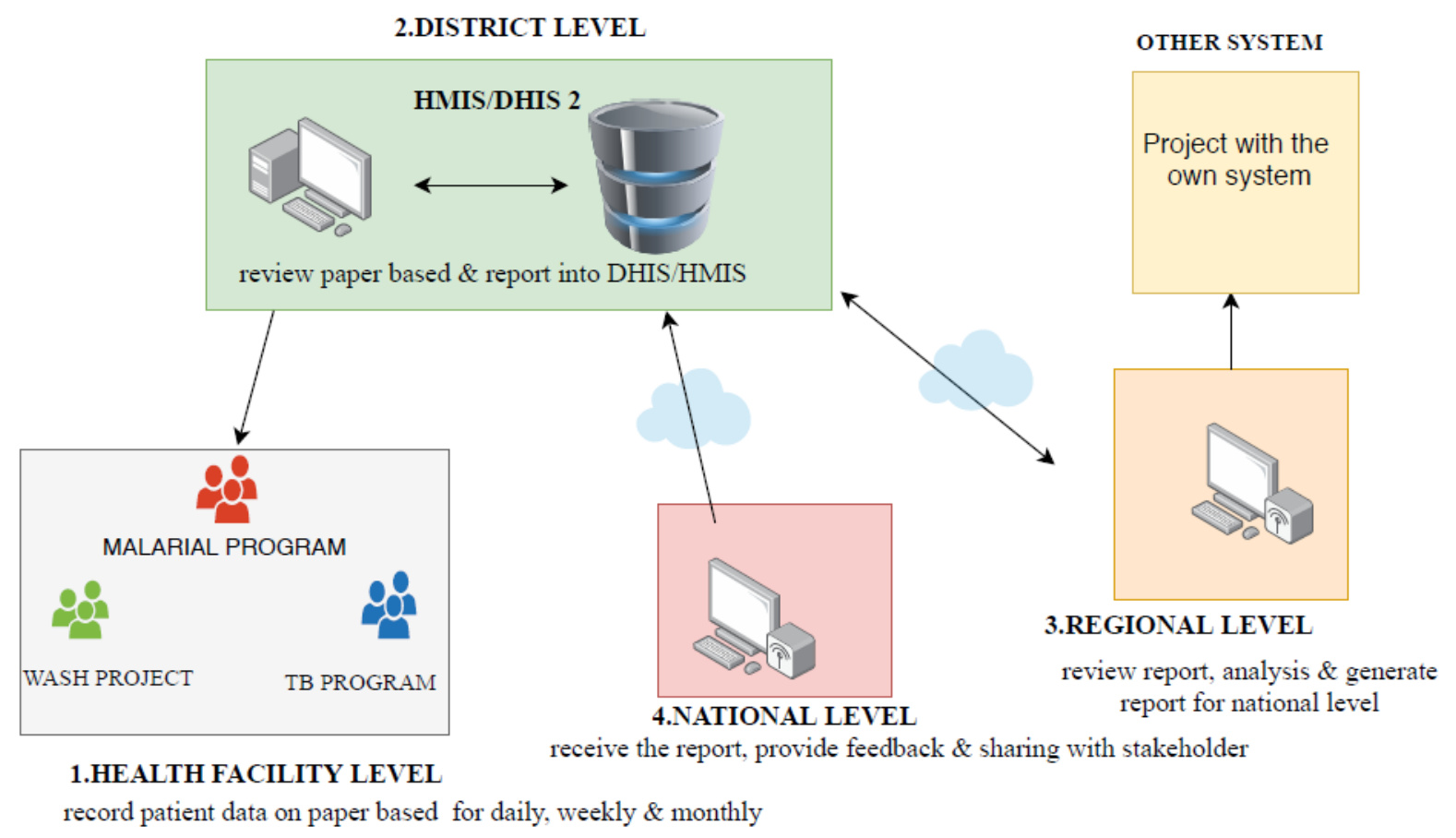

Fig.1. Present the current system on how they monitor and evaluate the government project at the ministry of health in Tanzania 


\section{Result from Document Review}

We review the necessary data or information that are needed when the project is registered in the system and we identify that some information is not there such as financial fund details and other stakeholder who are involved in projects are not included in the system.

In the ministry of health, every project has its own indicators and targets but sometimes can be similar.

\section{DESIGNED SOLUTION}

Based on the study findings, A web-based M\&E system is proposed to monitor and evaluate projects at the ministry of health. The system contains three modules, Projects registration module through which system administrator will be able to add and manage all users/members (project members or project teams, project coordinator, M\&E staff, accountant and donor fund/partners/other stakeholders of the project and other employees). The project manager will register project information such as; project title, location, the time frame of the projects, financial document/budget of the project and; browse/upload available information related to their projects and project activities.

In projects tracking module, the $M \& E$ staffs are the one who will add/update indicator of the project. The accountant will add/update the activities budget for every project in the system. The project members will enter basic data/information (multimedia data), pictures that are taken at different sites will be submitted to the system. Then, M\&E staff will review this data/information to check the indicators and targets for each activity to track the performance/progress of different projects and automatically the percentage or graph will be created.
Also, the system will offer additional functions such as providing an interface and workflow for project teams to submit their reports electronically.

The project status module will be designed in such a way that it gives alerts on failure or success of different projects and will automatically send the percentage before/after the deadline of projects as it detects risk and gives early warning alerts to the project team members and stakeholders. Fig. 2 presents the proposed system.

The proposed system will use the existing hardware which is used for DHIS/HMIS, but it may require/need some additional hardware for the project activities. The system will be user-friendly in such that it needs less effort for novice users to be familiar with it and does not require professional skills to understand how to use. The system updates will not a big issue since the system is a web-based tool; the system admin will need to update the online server so that all users can access the latest version.

\section{A. Functional Requirement for Web-Based Monitoring and Evaluation System for Government Projects}

The functional requirements describe the expected behavior of the proposed system in terms of tasks/services/operation to be performed by the system and the use case diagram to describe actors' activities and actions. Users have different privileges to access the system's features. Functional requirements for web applications are classified according to various design aspects such as visual elements of the web site, navigational structure and user interface.

The system administrator: Will log in and register all user of the system, responsible for defining and giving different privileges to all users of the system and every user must have a username and password to login the system.

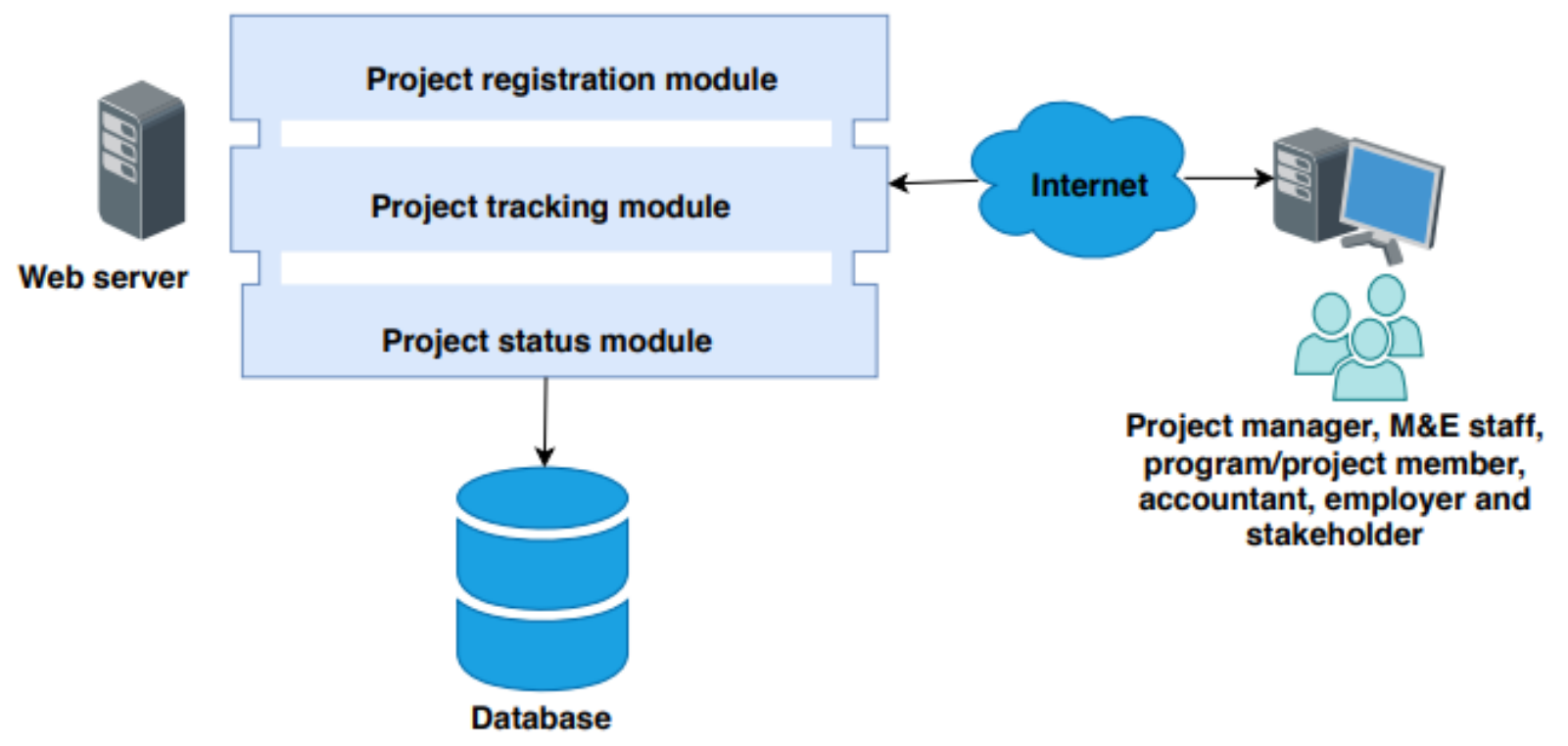

Fig.2. The designed solution for a web-based M\&E system for government projects at the ministry of health in Tanzania 
The project manager: He/she will register a new project to the system, including code number and title/type of project, location and timeframe/period of the project, the source of the project fund, all partners/support/donor funds and project activities.

Monitoring and evaluation officers: Add/update indicators for project activities and targets of the project, either by quarterly bases or year. M\&E will review and check the data which are entered by program members to track the progress of the project and to measure performance by looking the activities and indicator of the project and generate the report by either quarterly based or a year or depend on the nature of the project to the national level purpose.

Accountant officers: add/update financial document record/budget for project activities and verify if the accounting function was correctly captured.
Project members: In the system, the program members or project teams will have the privilege to perform their specific tasks of entering data/information with attachment either by weekly, monthly, quarterly bases in the system.

All registered users: Will be able to view the deadline warning, the status of the projects, alert information before/after the project to be completed as well as the percentage of success/failure of the project and project reports.

Donor/partner/national level at the ministry of health: They will provide feedback from the generated report. Further, they will view various reports from the projects they support. They can see the progress of reports and enquire more information from the project manager if needed. Fig. 3 presents the use case diagram of the proposed system.

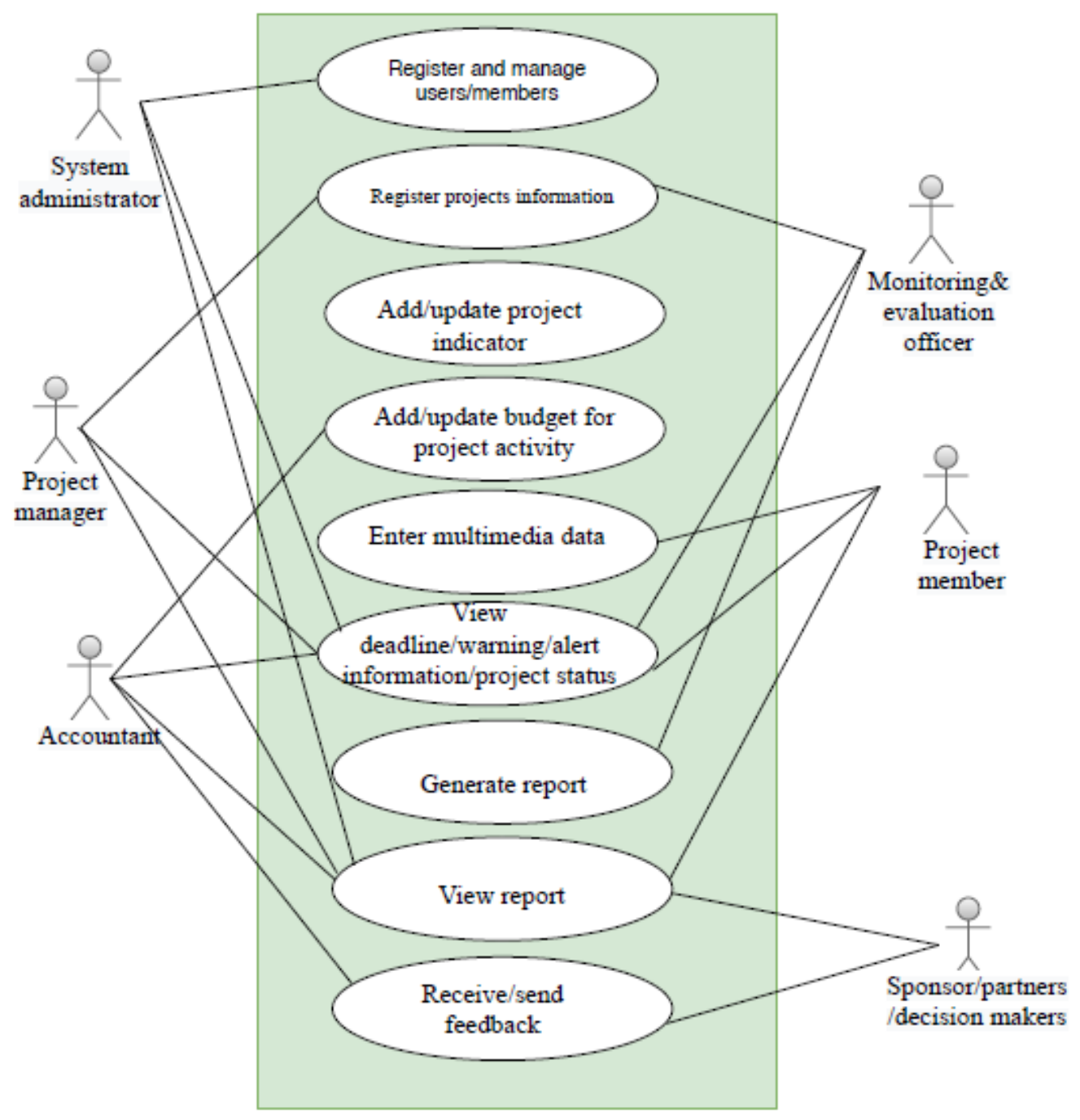

Fig.3. Use case diagram for proposed system 
B. Nonfunctional Requirement for Web-based Monitoring and Evaluation System for Government Projects

The nonfunctional requirement is not a concern with the function of the system or what program should do, but it deals with how it should work and it considers the quality attribute of the system that users care by looking the degree of satisfaction measure success or failure of the system.

Performance: The system will be required to support many terminals simultaneously without failure and handle multiple users without contradiction or break by using a fast server to handle traffic and provide crossbrowser compatibility.

Usability: All users will be satisfied with the usability of the website without any specialized training and be able to complete different tasks without failure.

Reliability: A web system will be capable to maintain its performance every time and be assured by making recoverable, website robust and available under adversity

Security: The system will manage the services and data in such that protection information from external attacks using authentication, authorization and encryption.
Interoperability: The system will be interoperable with existing systems at the ministry. It will API that will allow other systems to fetch data from it and it will be able to read structured documents such as XML.

Maintainability: The maintenance or any modification to the system for the sake of bug fixing or the addition of some new functionality will not cause the website to shut down more than once in 24 hours.

Flexibility: The system will have the ability to add the new notification/status of projects before and after the deadline.

Recovery: The system will be able to recover after some damage.

\section{Data Flow Diagram}

Dataflow diagram is the process used to show how data will be flow between actors [30]. In this study, the context diagram (level 0) shows the flow of information between external entities and proposed system (Fig. 4.) The data flow diagram (level 1) represent the flow of information, all process involved in each stage and the data stored involved when this process complete. Fig. 5 presents the data flow diagram for monitoring and evaluation system for ministry of health project in Tanzania.

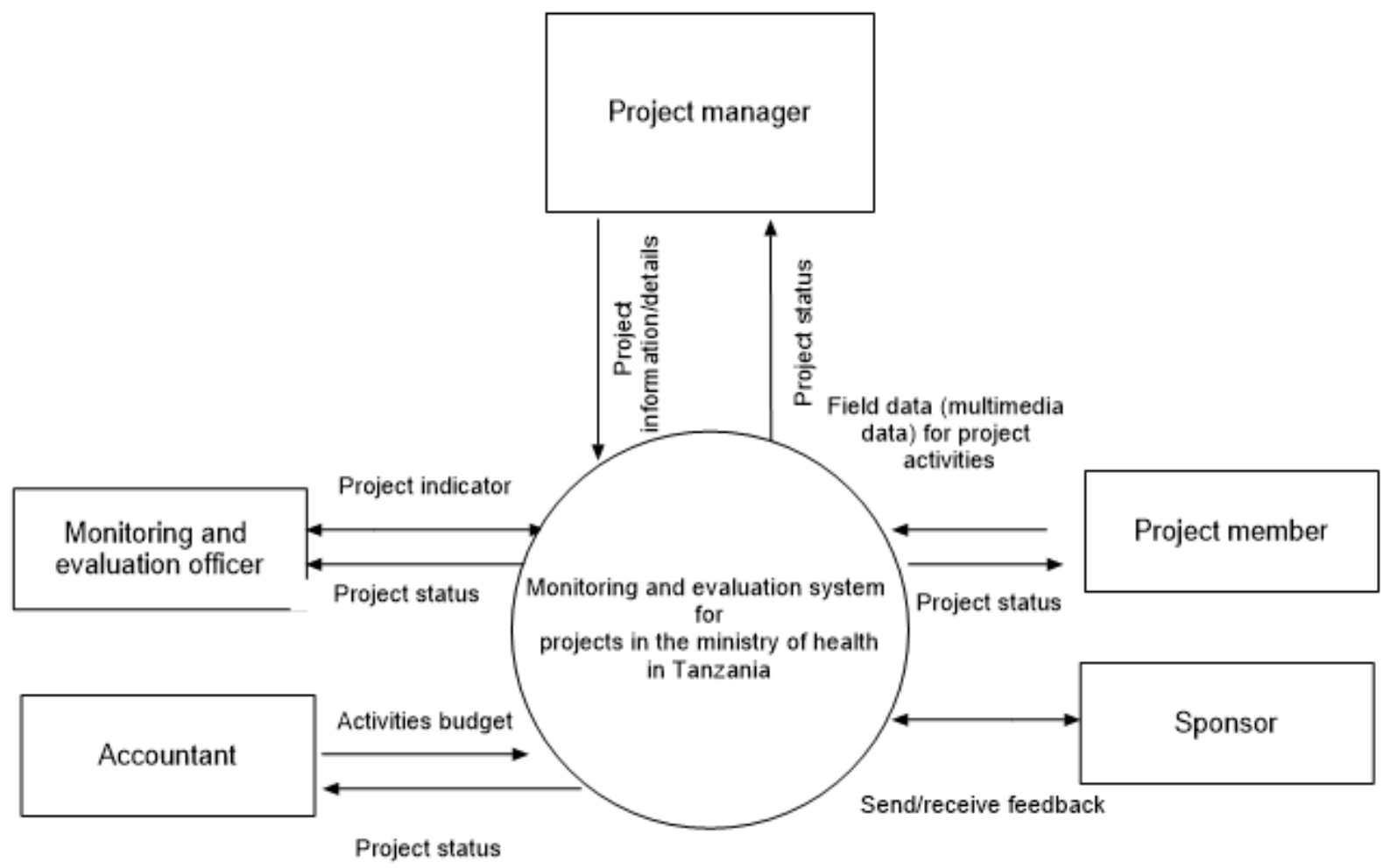

Fig.4. Context diagram for monitoring and evaluation system for ministry of health project in Tanzania. 


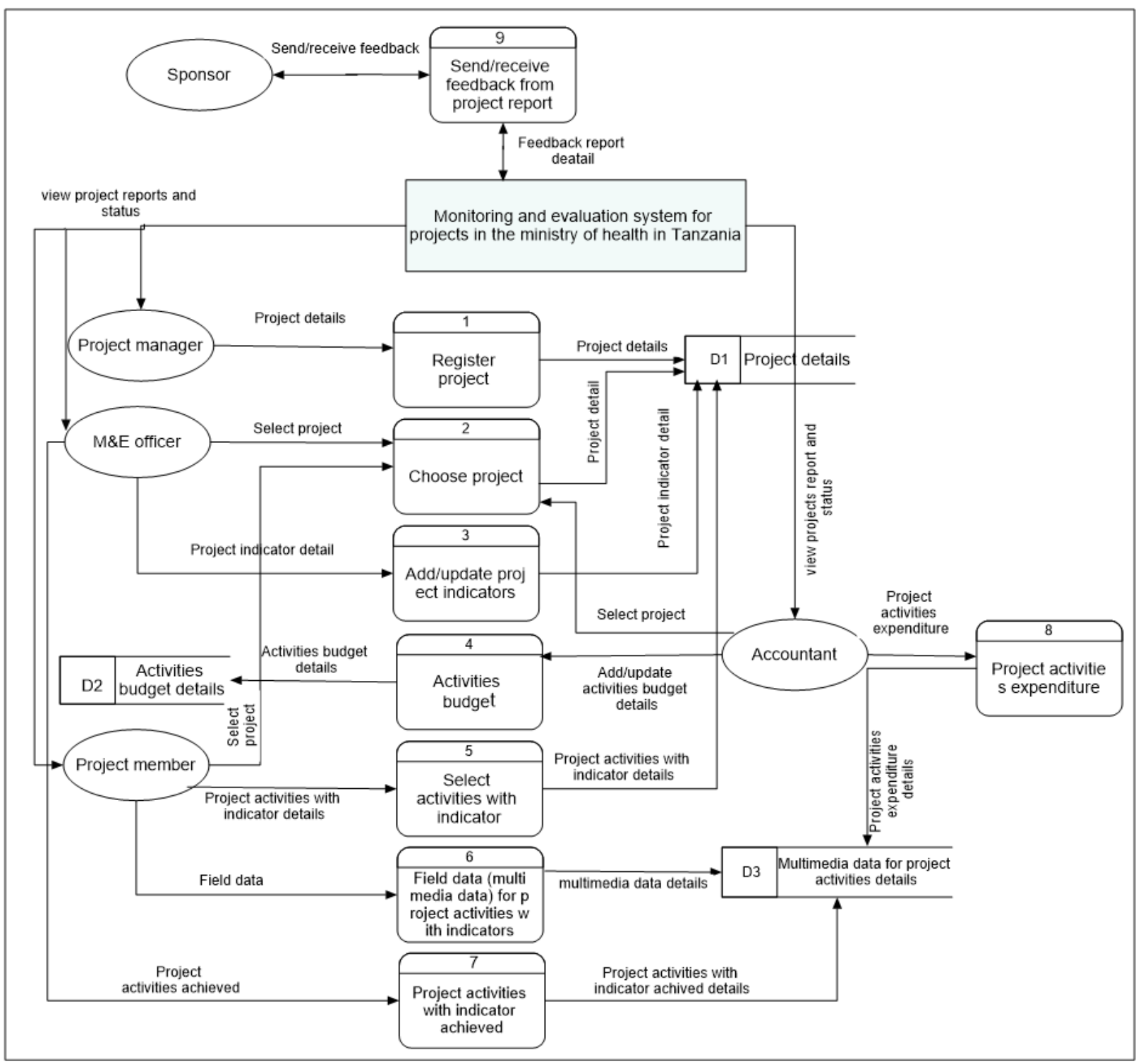

Fig.5. Data flow diagram for monitoring and evaluation system for ministry of health project in Tanzania.

\section{Database Schema}

The database schema is the structure or logical presentation of the database created by the database management system. It provides the structure of the database architecture and graphical view. It defines how data are organized and the relations among them are associated. The logical diagram in database schema [31] it comprises tables, entities, attribute and relationship between the tables. The database schema of the developed solution is presented in Fig. 6. 


\begin{tabular}{|c|c|c|}
\hline \multicolumn{2}{|c|}{ activity_attachement } & project_member_log \\
\hline \multicolumn{2}{|c|}{ activity_attachement_id } & member_log_id \\
\hline & act_code & log_project_member_ \\
\hline aca_attachement & act_description & log_prm_position \\
\hline aca_filetype & act_project_code & log_date \\
\hline aca_description & act_start_date & \\
\hline donor & act_finish_date & \\
\hline \begin{tabular}{|l|} 
donor_id \\
\end{tabular} & act_status & project_member \\
\hline \multirow{2}{*}{\begin{tabular}{|l|} 
don_code \\
don_description \\
\end{tabular}} & act_budget & project_member_id \\
\hline & act_expenditure & prm_member_email? \\
\hline \multirow[t]{2}{*}{\begin{tabular}{|l|} 
don_country \\
\end{tabular}} & & prm_activity_code \\
\hline & project & prm_position \\
\hline \multirow{5}{*}{\begin{tabular}{|l|} 
project_donor \\
project_donor_id \\
prd_project_code \\
prd_donor_code \\
prd_amount \\
\end{tabular}} & project_id & \\
\hline & pro_code & \\
\hline & pro_title & project_position \\
\hline & pro_location & position_id \\
\hline & pro_description & prp_position \\
\hline \multirow{2}{*}{\begin{tabular}{|l|} 
project_status \\
status_id \\
status_name \\
tbl_users \\
\end{tabular}} & pro_duration & \\
\hline \multirow{4}{*}{\begin{tabular}{|l|} 
project_status \\
status_id \\
status_name \\
\end{tabular}} & pro_start_date & \\
\hline & pro_finish_date & member \\
\hline & pro_budget & member_id \\
\hline & pro_expenditure & mem_email \\
\hline & \begin{tabular}{|l|} 
pro_status \\
\end{tabular} & mem_check_number \\
\hline \multirow{2}{*}{\begin{tabular}{|l} 
userld \\
email
\end{tabular}} & & mem_first_name \\
\hline & project_indicators & mem_middle_name \\
\hline $\begin{array}{l}\text { email } \\
\text { password }\end{array}$ & pind_id & mem_surname \\
\hline name & pind_name & mem_dob \\
\hline mobile & pind_pro_code & mem_gender \\
\hline roleld & completion_score & mem_office_affiliation \\
\hline isDeleted & & mem_address \\
\hline status & & mem_phone1 \\
\hline \begin{tabular}{|l} 
createdBy \\
createdDtm
\end{tabular} & & mem_phone2 \\
\hline \multirow{2}{*}{\begin{tabular}{|l} 
createdDtm \\
updatedBy
\end{tabular}} & & mem_createdBy \\
\hline & & mem_createdDate \\
\hline \begin{tabular}{|l|} 
updatedBy \\
updatedDtm \\
\end{tabular} & & mem_updatedBy \\
\hline & & mem_updatedDate \\
\hline
\end{tabular}

Fig.6. The database schema for developed solution

\section{DISCUSSION AND CONCLUSION}

Discussion: Based on the study findings, the challenges revealed by respondents, most of them agree to develop the electronic monitoring and evaluation system which will help to reduce the manual works, improve cooperation among the ministry departments, stakeholders, donor fund and partners, and to improve the implementation progress of success and well performing projects at the ministry of health in Tanzania. Moreover, the proposed system will improve the quality of data and simplify the process of data collection.

Limitation: The web-based monitoring and evaluation system for government project will be developed by using the software requirements collected at the ministry of health in Tanzania, to assist the monitoring and evaluation officials and other stakeholder in making a timely decision regarding the monitoring and evaluation of health projects in the ministry. However, other ministries overseeing non health projects might need to extend the results of this research to be applicable in their projects.

Conclusion: In this study, we have archive to analyze a current monitoring and evaluation system of various government projects at the ministry of health in Tanzania and come up with a proposed solution that is significant to the government projects/program at the ministry of health. The proposed system will minimize challenges and the study showed that the proposed solution is 
important to the different/various users, like; stakeholders decisions and policy makers who review and track the progress of a given program/project.

Future work will involve the development of a webbased monitoring and evaluation system for the ministry of health projects in Tanzania.

\section{ACKNOWLEDGMENT}

The authors wish to thank Ministry of health and Social Welfare for facilitating the data collection in the health projects in Tanzania government. This study was funded by African Development Bank.

\section{REFERENCES}

[1] MoHSW. THE UNITED REPUBLIC OF TANZANIA Tanzania National eHealth Strategy. 2012;(May 2013).

[2] Crop C, Foundation TM. Integrated Monitoring , Evaluation , \& Planning Handbook. 2017;

[3] Tengan C, Aigbavboa C, Thwala D. Conceptual description of the key determinants of effective monitoring and evaluation system. Adv Intell Syst Comput. 2019;785:117-24.

[4] PMBOK. A guide to the Project Management Body of Knowledge. 2001

[5] Attah R, Barca V, Macauslan I, Pellerano L, Ragno LP, Riemenschneider N, et al. How to move beyond the impact evaluation trap? Challenges and solutions for the setting up of comprehensive M\&amp;E systems for Social Protection Programmes. 2015;0186520730:1-28. Available from: http://www.opml.co.uk/sites/default/files/Working Paper ME for SP_FINAL.pdf

[6] Landicho JA. A web-based geographical project monitoring and information system for the road and highways. J Electr Syst Inf Technol [Internet]. 2018;5(2):252-61. Available from: http://dx.doi.org/10.1016/j.jesit.2016.10.011

[7] Sanga. Web-based System for Monitoring and Evaluation of Agricultural Projects '. 2014;(January 2013).

[8] MoHSW. Ministry of Health and Social Welfare: Strengthening Health Information System. 2010;

[9] Ministry of Health \& Social Welfare. THE UNITED REPUBLIC OF TANZANIA MINISTRY OF HEALTH AND SOCIAL WELFARE Tanzania National eHealth Strategy. 2012;(May):44.

[10] Ministry of Health (HSSP_III_2009-2015). Mid Term Review of the Third Health Sector Strategic Plan. 2015;(October 2013).

[11] United THE, Of R, Health MOF, Welfare S. the United Republic of Tanzania Ministry of Health and Social Welfare National Health and Social Welfare. 2018;2018(November 2013):1-61.

[12] Nyaboke ND. FACTORS INFLUENCING IMPLEMENTATION OF MONITORING AND EVALUATION IN WATER PROJECTS IN KENYA : A CASE OF NON-GOVERNMENTAL ORGANISATION WATER PROJECTS IN KAJIADO COUNTY BY DEVINER NYABOKE NYAMONGO A Research Project Report submitted in partial fulfillment of. 2017;

[13] Mkama W. Evolution of Natural Resource Programs Performance Management in Tanzania: A Review of Monitoring , Evaluation and Learning ( MEL ) Aspects and Policy Recommendations Wilbard Mkama. 2017.
[14] Micah NJ, Luketero SW. Monitoring and Evaluation Systems and Performance of Non-Governmental Based Maternal Health Projects in Bungoma South Sub-County , Kenya. 2017;13(23):11-38.

[15] Wachaiyu VW. Monitoring and Evaluation Factors Influencing Success of Development Projects: a Case of Starehe Sub-County, Kenya. 2016.

[16] Unesco. Designing effective monitoring and evaluation of education systems for 2030: A global synthesiss of policies and practices. 2016.

[17] Amos W. Determinats of effectiveness of a monitoring and evaluation system for projects : A case of AMREF Kenya wash. 2015;

[18] Moyne MM, Herman M, Gajos KZ, Walsh CJ, Holland DP The development and evaluation of DEFT, a web-based tool for engineering design education. 2018;1382(c):1-8.

[19] Kiboi GK, Kilonzo DJ, Iravo PM. Determinants of Effective Monitoring and Evaluation in Health Service Delivery: A Case of Nairobi City County Health Facilities. Int J Manag Commer Innov ISSN. 2018;6(1):231-45.

[20] Ahmed AN, Magdi DA. The Impact of Electronic Monitoring and Evaluation System on Organization Performance Applied on Egyptian International Trade Point Sector Ministry of Trade \& Industry in Egypt. 2017;02(05):1-11.

[21] Cheung SO, Suen HCH, Cheung KKW. PPMS: A Webbased construction Project Performance Monitoring System. Autom Constr. 2004;13(3):361-76.

[22] Sanga C, Fue K. Web-based System for Monitoring and Evaluation of Agricultural Projects'. 2014;(July).

[23] Evaluation G. Data Collection for Program Evaluation Overview of Data Collection Resources. 2001;

[24] [24] NTLP. The United Republic of Tanzania Ministry Of Health Community Development, Gender, Elderly and Children The National Tuberculosis and leprosy Programme Annual report for 2016. 2016;1-48.

[25] Bryman A. Social Research Method (Fifth Edition). 2016;

[26] Nyumba TO. The use of focus group discussion methodology : Insights from two decades of application in conservation. 2018;(January).

[27] Ministry of Health and Social Welfare. UNITED REPUBLIC OF TANZANIA Ministry of Health and Social Welfare ( MoHSW ) PROPOSAL TO STRENGHERN HEALTH INFORMATION SYSTEM [ HIS ] Executive Summary. :1-59.

[28] Kumalija CJ. Update of M\&E Strengthening Initiatives (M\&E SI) A Tanzanian Platform for Health Information and Accountability. 2017;(6):1-86.

[29] Mci W, Internet W. Monitoring and Evaluation: Some Tools, Methods, and Approaches. Ser Manuales .... 2002;

[30] Svobodová L, Černá M. Project management model with designed data flow diagram: The case of ICT hybrid learning of elderly people in the Czech Republic. Lect Notes Comput Sci (including Subser Lect Notes Artif Intell Lect Notes Bioinformatics). 2018;11056 LNAI:399-408.

[31] Solihin W, Eastman C, Lee YC, Yang DH. A simplified relational database schema for transformation of BIM data into a query-efficient and spatially enabled database. Autom Constr [Internet]. 2017;84(August):367-83. Available http://dx.doi.org/10.1016/j.autcon.2017.10.002 


\section{Authors' Profiles}

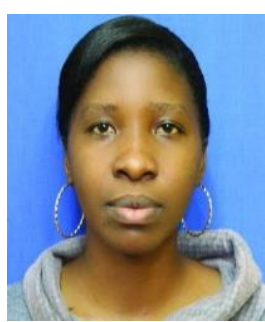

Mpawe N. Mleke received her BSc in Information System and Network Engineering from St. Joseph University in Tanzania, in 2014. She then worked with Kiota Women Health and Development (KIWOHEDE) as Monitoring and Evaluation Officer at Mwanza in 2016 before joined the NMAIST.

Current, she is pursuing Master 's Degree in Information and Communication Science and Engineering (ICSE) at Nelson Mandela -African Institution of Science and Technology (NMAIST)

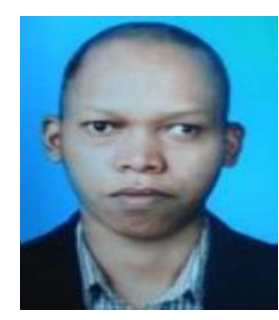

Dr. Mussa Ally Dida is a Lecturer at Nelson Mandela African Institution of Science and Technology (NM-AIST). $\mathrm{He}$ acquired his B.Sc. in Computer Engineering and Information Technology from University of Dar es Salaam (UDSM), M.Sc. in Telecommunication Engineering from University of Dodoma (UDOM) 2008 and 2011 respectively and a Ph.D. in Information and Communication Engineering from Beijing Institute of Technology (BIT), Beijing, China in 2017.

His research interests include signals and communication systems analysis, modeling and optimization, online system development and currently working in farmers' extension support system and private school enrollment and communication systems.

How to cite this paper: Mpawe N. Mleke, Mussa Ally Dida, " A Survey of Monitoring and Evaluation Systems for Government Projects in Tanzania: A Case of Health Projects", International Journal of Information Engineering and Electronic Business(IJIEEB), Vol.12, No.1, pp. 8-18, 2020. DOI: 10.5815/ijieeb.2020.01.02 